\title{
Estructuras contractuales en el sector de las finanzas populares en el municipio de Querétaro en México
}

\author{
Cenobio Javier Cárdenas Félix, Julia Hirsch y \\ Graciela Lara Gómez
}

\section{RESUMEN}

A la luz de la teoría de contratos, como parte de la microeconomía y de la ciencia de la economía en general, la presente investigación se orienta al estudio de las relaciones contractuales en el sector de las finanzas populares, particularmente en el Municipio de Querétaro, México. En ésta se identifican las metodologías e instrumentos que son utilizados por las organizaciones de las finanzas populares para atenuar los efectos de la información asimétrica que está presente entre las partes contractuales. También es importante la contribución que se hace a manera de propuestas, al contrastar lo observado en campo con lo que la teoría señala, sobre las diferentes alternativas que las organizaciones tienen para perfeccionar sus formas de trabajar con el fin de incidir en amplios sectores de población que todavía demandan servicios financieros.

PALABRAS CLAVE: Asimetrías de la información, créditos, organizaciones de las finanzas populares, metodologías crediticias.

CLAVES ECONLIT: G200, G210, G230, G280, G290, P130.

Cómo citar este artículo: CÁRDENAS, C.J., HIRSCH, J. \& LARA, G. (2015): "Estructuras contractuales en el Sector de las Finanzas Populares en el Municipio de Querétaro en México", CIRIECEspaña, Revista de Economía Pública, Social y Cooperativa, 84, 133-162.

Correspondencia: Cenobio Javier Cárdenas Félix, Maestría en Finanzas Públicas por el Instituto Nacional de Administración Pública y Licenciatura en Economía por la Universidad Autónoma Metropolitana Unidad Iztapalapa (UAM-I) Ciudad de México; Julia Hirsch, Doctora en Economía por la Goethe University en Frankfurt, Alemania, miembro del Sistema Nacional de Investigadores (S.N.I. Nivel 2) y Profesora-Investigadora a tiempo completo de la UAQ; Graciela Lara Gómez, Doctora en Estudios Organizacionales por la UAM-I, Maestra en Derecho Fiscal y Maestra en Impuestos por la UAQ, Miembro del Sistema Nacional de Investigadores (S.N.I. Nivel 1) y Profesora-Investigadora de tiempo completo en la UAQ. E-mail de contacto: jcardenasf18@ hotmail.com. 


\title{
Structures contractuelles dans le secteur des finances populaires dans la commune de Querétaro au Mexique
}

RÉSUMÉ : Compte tenu de la théorie des contrats, cette dernière faisant partie de la microéconomie et de la science de l'économie en général, cette recherche porte sur l'étude des relations contractuelles dans le secteur des finances populaires, en particulier dans la commune de Querétaro, au Mexique. Elle permet d'identifier les méthodes et instruments utilisés par les organisations des finances populaires afin d'atténuer les effets de l'information asymétrique présente entre les parties contractuelles. La contribution apportée sous forme de propositions est également importante, en comparant les observations sur le terrain ou issues de la théorie, sur les différentes alternatives qu'ont les organisations pour perfectionner leurs manières de travailler afin d'avoir un impact dans de grands secteurs de population nécessitant encore des services financiers. crédit.

MOTS CLÉ : Asymétries de l'information, crédits, organisations des finances populaires, méthodologies de

\section{Contractual structures in the Popular Finance Sector in the Municipality of Querétaro (Mexico)}

\begin{abstract}
In the light of contract theory, as a part of microeconomics and of economics in general, this research focuses on the study of contractual relations in the popular finance sector, particularly in the city of Queretaro, Mexico. The study has identified the methods and tools used by popular finance organizations to mitigate the effects of the asymmetry of information between the parties to the contract. Another important contribution is the suggestions prompted by comparing the findings of the field study with theory-based predictions about the different alternatives that organizations have to improve the ways they work in order to reach broader sectors of the population that still require financial services.
\end{abstract}

KEY WORDS: Information asymmetries, credit, microfinance organizations, lending methods. 


\section{1.- Introducción}

Las finanzas populares por mucho tiempo en México han sido estudiadas con un enfoque de desarrollo económico o en su defecto bajo una concepción de antropología financiera y su impacto en la pobreza ${ }^{1}$. En esta ocasión se estudia el tema desde la perspectiva de las ciencias económicas y específicamente de la microeconomía para examinar las relaciones contractuales entre los prestatarios y los prestamistas ante una problemática de pronunciada información asimétrica.

El fenómeno de las asimetrías de la información se refiere a la relación que se entabla entre oferente y demandante en el mercado, donde una de las partes tiene ventaja sobre la otra al contar con información que la segunda desconoce. Al suscitarse el ocultamiento de la información y ser percibida de manera distinta por los actores económicos, se generan perturbaciones que conducen a desequilibrios o fallas de mercado cuyas manifestaciones se presentan en sus más diversas formas. Para atenuar este problema, se recurre a la elaboración y puesta en práctica de contratos adecuados que prevean las condiciones, mecanismos e incentivos que permitan alinear los intereses de las partes.

En el mercado de las finanzas populares en el país, las asimetrías de la información están presentes. Se conciben a las finanzas populares como el sector de ahorro y crédito popular o banca social, que de acuerdo con la Comisión Nacional Bancaria y de Valores (CNBV) se ha abocado por más de 60 años a proporcionar servicios financieros a una parte del segmento de la población desatendida por la banca tradicional (Comisión Nacional Bancaria y de Valores, s.f., a). A partir del año 2000, en México se empezó a difundir en el ambiente del sector el concepto de finanzas populares de una manera genérica para incluir en el contenido de su materia a las entidades del sector de ahorro y crédito popular, las microfinanzas y las finanzas sociales.

Por lo que se refiere a las entidades del sector de ahorro y crédito popular, incluyen a las Cooperativas de Ahorro y Préstamo y a las Sociedades Financieras Populares, cuyos objetivos principales consisten en facilitar a sus miembros el acceso al crédito, apoyar el financiamiento de micro, pequeñas y medianas empresas, así como propiciar la superación económica de sus miembros y de las comunidades en las que operan (Comisión Nacional Bancaria y de Valores, s.f., b).

El término microfinanzas comprende la actividad que se realiza para otorgar servicios financieros en pequeña escala, fundamentalmente crédito y ahorro, proporcionados a aquellos que se dedican a la agricultura o a la pesca o a la ganadería; a los propietarios de pequeñas empresas 0

1.- Son diversos los estudios realizados en la materia, véase entre otros a Mansell (1995), González y Alpizar (2006), Imperial y Ramírez (2001), Campos (2005), Gavito (2005) y Conde (2005). 
microempresas en las que se producen, reciclan, reparan o venden bienes; a las personas que proporcionan servicios, que trabajan por un sueldo o una comisión; a los que obtienen sus ingresos rentando pequeñas parcelas de tierra, vehículos, animales de labranza o maquinaria y herramientas a otros individuos o grupos en las localidades rurales o urbanas, en los países en vías de desarrollo. En general abarca cualquier tipo de servicios financieros proporcionados a los hogares y empresas de bajos ingresos, en cuyo caso se estaría poniendo en práctica el uso del microcrédito (Robinson, 2004).

Las finanzas sociales hacen referencia a la aplicación de las finanzas con dimensión humana, que orienta sus esfuerzos para extender los servicios financieros a las personas excluidas con impacto en la promoción de un mejor empleo y en la reducción de la vulnerabilidad de los trabajadores pobres que se apoyan en la gestión apropiada de créditos, riesgos y microseguros, entre otros servicios innovadores (Organización Internacional del Trabajo, s.f.).

El artículo en cuestión tiene como propósito fundamental evaluar las relaciones contractuales que establecen las organizaciones del sector financiero popular en el Municipio de Querétaro con los prestatarios que atienden, en condiciones de información asimétrica. En este sentido, se exploran las circunstancias de un mercado caracterizado a nivel nacional por la complejidad de su funcionamiento y por la prominente reserva en el suministro de la información promovida por el Estado regulador, situación que obedece a un contexto complejo de transición de las instituciones prestamistas para ajustarse a lo que las disposiciones legales establecen. Por este motivo, el estudio se aborda desde lo local en el Municipio de Querétaro, toda vez que en este Ayuntamiento se localizan diferentes experiencias históricas de éxito y fracaso del funcionamiento de las organizaciones de las finanzas populares, como reflejo de lo que se vive en el país, que se distingue actualmente por la existencia de una amplia variedad de dichas instituciones, algunas de las cuales han logrado adquirir su formalidad ante las disposiciones legales que las regulan, otras vienen realizando esfuerzos para conseguirlo y unas más que para subsistir se han visto obligadas a dejar de brindar determinados servicios a la población como la captación de ahorros para evitar violentar las leyes establecidas.

En concreto, se exponen los resultados relevantes de la investigación empírica efectuada en 16 instituciones de las finanzas populares en el Municipio de Querétaro en el Estado de Querétaro, México. Derivado de ello, se muestra que a diferencia de las predicciones teóricas y las experiencias internacionales en el sector de las finanzas populares, las organizaciones prestamistas exigen en su relación con el prestatario, como soporte de las operaciones crediticias, garantías con valor comercializable predominantemente elevadas respecto del monto del préstamo. También se destaca que aunque trabajan con diversas metodologías crediticias para mitigar los efectos de la información asimétrica, fundamentalmente emplean la tecnología de préstamos individuales, como una opción de esquema de servicio muy similar al que utilizan los bancos comerciales.

El artículo se ha estructurado de la siguiente manera: la sección 2 contiene un breve panorama teórico sobre las asimetrías de la información y en la 3 se aborda la metodología. En la sección 4 se 
realiza el análisis de la información en el contexto del fenómeno y posteriormente se expone la discusión de algunos resultados. El artículo finaliza con las conclusiones sobre los aspectos relevantes de la investigación.

\section{2.- Perspectiva Teórica sobre las Asimetrías de la Información}

Es sabido que en el mundo real de la economía, los mercados se encuentran entrelazados. Se presume que en ellos está presente la información asimétrica, que consiste en el hecho de que al interactuar los agentes económicos en los mercados, una de las partes posee información que la otra desconoce, creándose de esta manera condiciones desiguales en la relación económica que entablan, por lo que se propician ventajas y cierto sentido de oportunismo para uno de los participantes que conducen a ineficiencias de mercado (Stiglitz, 2002; Stiglitz, 2007; y Stiglitz, 2010).

Existen estudios diversos sobre este fenómeno en diferentes mercados, como ocurre con el de los automóviles, los seguros, el ámbito laboral, el de la educación, la bolsa de valores, el comercio internacional, entre otros. Todo apunta a que lo normal es que los mercados sean imperfectos, a diferencia de lo que los economistas clásicos como Adam Smith, David Ricardo, Jean Baptiste Say, John Stuart Mill y León Walras expusieron y que derivaron en la teoría del equilibrio general de los mercados (Akerlof, 1970; Leland and Pyle, 1977; Stiglitz and Weiss, 1981; y Stiglitz, 2002).

El fenómeno de la información asimétrica se inscribe en el campo de las ciencias económicas, específicamente en la microeconomía, en lo que se ha dado en llamar economía de la información y ha sido un tema de interés de grandes economistas como Vickrey (1961), Stigler (1961), Akerlof (1970), Spence (1973) y Stiglitz (2002)2. Los últimos tres recibieron el premio nobel de economía en el año 2001 por sus aportaciones a la economía de la información. De ellos, Stiglitz el más reciente y uno de los más prolíficos en la materia, en diferentes artículos ha venido trabajando a fondo sobre las imperfecciones del mercado (Rothschild and Stiglitz, 1976; y Helmann and Stiglitz, 2000). Se define a la economía de la información como el estudio de las consecuencias de la existencia de la asimetría de información entre diversos agentes económicos, sobre la forma en que estos se organizan y la eficiencia en la relación que establecen (Macho y Pérez, 2009).

2.- Vickrey marcó la pauta en su calidad de pionero de esta rama del conocimiento al contribuir a lograr la eficiencia en el mercado de subastas selladas para revelar la conducta del subastador usando como mecanismo de incentivo que erogaran sobre el precio inmediato anterior en su calidad de costo de oportunidad. Stigler, premio nobel de economía en 1982, aborda la información como un bien sujeto a las condiciones de mercado y a un costo de oportunidad. Akerlof en su más famoso artículo 'El Mercado de los Limones', considera la economía de la información al estudiar los factores de incertidumbre, calidad de los bienes y costo económico de la honradez, al mismo tiempo que incluye la función de utilidad, su maximización, la racionalidad y el factor riesgo; así como el conocimiento y desconocimiento de la información. Por lo que se refiere a Spence, analiza los mercados con información asimétrica; afronta los problemas de selección adversa y de la educación como factor de señalización en términos de productividad en el mercado de trabajo. 
En el mercado de la intermediación financiera, la teoría identifica en las asimetrías de la información fundamentalmente dos tipos de problemas: la selección adversa y el riesgo moral (Stiglitz, 2002). Respecto a la selección adversa, el prestamista que en este caso se le concibe como el principal, antes de conceder el préstamo, tiene dificultades para distinguir la calidad del prestatario, que en este caso es el agente, particularmente sobre su trayectoria e intenciones. En cuanto al riesgo moral, que ocurre una vez que se ha otorgado el préstamo, el prestamista no sabe del todo cómo el prestatario usará los recursos, los riesgos que asumirá y que aumentan la probabilidad de impago ${ }^{3}$.

De manera más específica, de acuerdo con Armendariz y Morduch (2011), el mercado de crédito que atiende a los pobres se convierte en una realidad un tanto compleja dada la información incompleta de que las instituciones disponen sobre los prestatarios en cuanto al riesgo, esfuerzo y ganancia, además de la falta de colaterales en calidad de garantías. Dicho problema de la información oculta se presenta en diferentes etapas: la primera antes de conceder el préstamo porque no se conocen las características del prestatario; segunda, al momento de otorgarse y desconocer si el prestatario dará el uso adecuado al recurso; y tercera, la treta a que podría exponerse el prestamista por parte del prestatario sobre sus verdaderas ganancias para requerirle el pago completo e imponer sanciones.

La solución para resolver los aspectos ocultos de la información, radica en el diseño y puesta en práctica de contratos adecuados para cada tipo de relación crediticia que se genere en el mercado de la intermediación financiera ${ }^{4}$. En este sentido, tendrán que generarse distintas alternativas contractuales que incluyan los incentivos pertinentes que conduzcan al agente a revelar su información, controlar su proceder, recuperar el pago completo y en su caso establecer las penas correspondientes. Esta situación al manifestarse en el segmento de los excluidos por la banca comercial ${ }^{5}$, que se localiza en la base de la pirámide de intermediación financiera, es complicada y costosa si se trata de contar con la información requerida.

Ante una situación de mercado como a la que se enfocan las organizaciones de las finanzas populares caracterizada porque la población objetivo es de escasos recursos y en la que obtener la información acerca de los agentes implica altos costos, los montos de las transacciones son pequeños y los prestatarios cuentan con escasos activos comercializables para efectos de hacer las veces de colateral o carecen totalmente de ellos, y/o se encuentran excluidos de los servicios de la banca tradicio-

3.- Un tercer problema es el de la señalización, que no es objeto de estudio en este artículo y que consiste en la etapa de la relación cuando se han generado los rendimientos de la inversión y el prestamista podría no estar en condiciones de verificar la magnitud de ganancias, propiciando la posibilidad de engaño.

4.- De acuerdo con los diferentes estudios que se citan en el artículo, la teoría señala que si bien es cierto que los contratos son información observable por igual para ambas partes, corresponde al principal o prestamista exponer en el mercado la oferta de las estructuras contractuales y por consiguiente su diseño, de manera que el agente o prestatario toma o deja las opciones que se le presentan. Lo que interesa considerar en el análisis son los elementos contractuales enfocados a encontrar la combinación óptima del uso de las herramientas orientadas a mitigar los efectos de las asimetrías de la información. En tal sentido, es la institución prestamista la que tiene como tarea aminorar a través de los contratos las manifestaciones del problema que son las relativas a la selección adversa y riesgo moral (Stiglitz and Weiss, 1981). El Estado por su parte actuará como regulador y arbitro de la relación contractual.

5.- Este mercado está conformado preponderantemente por población que se encuentra desprotegida económicamente y en menor medida por ciertos sectores de la clase media baja que carecen de un empleo formal.

CIRIEC-España, Revista de Economía Pública, Social y Cooperativa

ISSN: 0213-8093

№ $84 / 2015$, pp. 133-162 
nal, dichas organizaciones tienen como tarea encontrar solución a estos problemas y generar los mecanismos compensatorios a la falta de garantías de los prestatarios. Para tal propósito, necesitan concebir nuevas formas más eficientes de conceder los créditos, como alternativa para romper el círculo vicioso que se genera por la falta de activos en calidad de garantías, eliminando los obstáculos que producen los elevados costos de transacción y superando los problemas de la información oculta. Aquí es donde radica la importancia de diseñar estructuras contractuales óptimas, que prevean los elementos, componentes y situaciones cuyas formas y contenidos estén orientados a mitigar los problemas de la información asimétrica.

Cabe destacar que la información motivo de la investigación se relaciona con las variables que son verificables. Los instrumentos son las opciones de que se valen las instituciones prestamistas para resolver situaciones problema, presumiblemente de riesgo de impago. Las metodologías crediticias por su parte, son las tecnologías o esquemas integrales que por su singularidad al instaurarse favorecen la atención de un segmento de mercado cuya población prestataria es especialmente diferente por las dificultades que presenta para acceder a los créditos. Dichas metodologías crediticias coadyuvan en el diseño contractual óptimo para atenuar las asimetrías de la información.

Al analizar la experiencia del sector de las finanzas populares y de acuerdo con autores como Egli (2004), Fischer and Gathak (2010), Olivier (2011) y Armendariz y Morduch (2011), se han desarrollado modelos sobre metodologías e instrumentos que influyen amortiguando los efectos de la asimetría de la información, tales son los casos del préstamo colectivo, la banca comunal, los préstamos individuales, el préstamo progresivo, los pagos frecuentes, el monitoreo, el préstamo vinculado al ahorro y las garantías 6 .

A manera de ejemplo, Armendariz y Morduch (2011) abordan la metodología de Responsabilidad Colectiva o préstamos colectivos, que se usa para atenuar el problema de la selección adversa que propicia que el prestamista incremente las tasas de interés y que puede llevar al racionamiento en el crédito. Con objeto de moderar dicha ineficiencia, como parte del modelo la institución de las finanzas populares adopta el esquema de responsabilidad colectiva o de préstamos colectivos.

Para explicar el funcionamiento de esta metodología del modo más simple posible, Armendariz y Morduch (2011) suponen que un prestatario es seguro con probabilidad $q$ y no seguro con probabilidad (1-q). La tasa de interés $R b$ que se establecerá será la que permita a la institución mantener las condiciones de equilibrio de ingreso y gasto. Para poder determinar esta tasa de interés, es importante pensar cuál será la tasa de repago de las diferentes agrupaciones.

6.- Los estudios sobre las experiencias del sector de las finanzas populares, realizados por Egli (2004) incluye las indagaciones efectuadas en Bangladesh, Bolivia y Guatemala; de Fischer and Gathak (2010) corresponden a países como Bangladesh, Bolivia, India, Filipinas, Estados Unidos y Uganda; por lo que se refiere a Olivier (2011), las investigaciones comprenden a países como Bangladesh, Sri Lanka, Sudáfrica, Kenia e India; y las que efectúan Armendariz y Morduch (2011) se sitúan en países como Bangladesh, Indonesia, Tailandia, Bélgica, Francia, Alemania, India, Filipinas, República Dominicana y México. 
Los beneficios ÿ del proyecto en condiciones de préstamos colectivos deben ser dos veces el monto del pago de la tasa de interés $R b$, es decir que $\ddot{y}>2 R b$, escenario que ocurre sólo de una manera aproximada en la vida real. Dado este supuesto, los grupos de los prestatarios no seguros sólo incumplirán si ambos proyectos fracasan lo que ocurre con una probabilidad de (1-p)*(1-p). La institución estará en condiciones de cobrar a los grupos de prestatarios seguros con una probabilidad $g=1$, mientras que a los grupos de los no seguros lo hará con una probabilidad de $g=1-(1-p)^{\wedge} 2$.

El pago esperado de la institución en equilibrio tendrá que ser igual a $k$ que es el costo del fondo de los bancos y que se expresa como sigue: $k=[q+(1-q) g] R_{b}$. Despejando, el costo del préstamo a los grupos será de $R_{b}=k /[q+(1-q) g]$ que al comparar con la tasa de interés de los préstamos individuales $R$, ésta se cobrará en dicho esquema como sigue: $R=k /[q+(1-q) p]$. De esta manera, se puede ver que como $g>p$, debido a que la probabilidad de pago en el esquema de responsabilidad colectiva g es más alta que en el de préstamos individuales $p$, toda vez que por su naturaleza al responder unos por otros se asegura el retorno del crédito, entonces la tasa de interés que se aplica con responsabilidad colectiva $R_{b}$ será menor a la que se utiliza con préstamos individuales $R$, esto es $R_{b}<R$. Por lo tanto, la consecuencia del problema de selección adversa que lleva a un aumento en las tasas de interés es atenuado.

\section{3.- Metodología}

La pertinencia de realizar el estudio en el Estado de Querétaro, obedece a la peculiaridad que éste tiene en cuanto a su desarrollo e historia. Con sus 18 municipios aporta el $2.1 \%$ al Producto Interno Bruto Nacional, es el asiento de un dinámico sector manufacturero ( $28.1 \%$ del PIB estatal) y cuenta con gran cercanía de la capital del país por lo que sirve de tránsito para las relaciones comerciales con el resto de las regiones y es receptor de importantes movimientos migratorios (Secretaría de Economía, s.f., a). El Municipio de Querétaro al estar conurbado con los municipios de Corregidora y el Marqués, en 2013 alcanzó a tener una población de 1,137,245 habitantes (Secretaría de Gobierno, s.f.). Al respecto se consideró este lugar para el desarrollo de la investigación, por ser un espacio territorial reflejo de las condiciones del país, favorecido históricamente para el desarrollo del mercado de las finanzas populares, por las recientes iniciativas de voluntad de los gobiernos para impulsar programas microfinancieros y de manera muy especial porque a pesar de contar con el $68 \%$ de las sucursales bancarias del Estado (Instituto Nacional de Estadística y Geografía, s.f., b), existe un número importante de organizaciones prestamistas como expresión de la atención a la fuerte demanda de población excluida de los servicios financieros. 
El estudio se basa en una investigación cuantitativa, cuyo objetivo general consistió en evaluar las relaciones contractuales que establecen las organizaciones del sector financiero popular en el Municipio de Querétaro con los prestatarios que atienden en condiciones de información asimétrica. En ese contexto, se planteó la siguiente hipótesis de la investigación: las organizaciones del sector financiero popular del Municipio de Querétaro utilizan estructuras contractuales de crédito especializadas para ajustarse a las características del mercado que atienden.

De un universo total estimado por la Comisión Nacional para la Defensa de los Usuarios de las Instituciones Financieras (CONDUSEF, 2011), de 850 entidades que existen en el país cuyas limitaciones para su operación son las que les impone cumplir el contenido del propio marco legal vigente, es decir la Ley de Ahorro y Crédito Popular (LACP), Ley para Regular las Actividades de las Sociedades Cooperativas de Ahorro y Préstamo y Ley General de Sociedades Cooperativas, hay 300 que operan y están en un proceso de adecuación para ajustarse a dichas disposiciones. De estas, 16 están establecidas en el Estado de Querétaro, de las cuales 8 operan en el Municipio de Querétaro. Existe otro segmento de instituciones que trabajan en el mercado, algunas sin estar obligadas a cumplir con las exigencias legales y otras evadiendo su obligatoriedad. Del total de las entidades formales y no formales ${ }^{7}$, de acuerdo con los registros del Instituto Nacional de Estadística y Geografía (INEGI), se identificó la presencia en el Municipio aproximadamente a 50 de ellas (Instituto Nacional de Estadística Geografía e Informática, s.f., a).

Ante la falta de certeza sobre la naturaleza financiera popular del universo de las organizaciones que operan en el Municipio, se hizo una depuración hasta llegar a una muestra representativa de 30 organizaciones, que para efectos de captación de la información sólo 16 de ellas respondieron, lo que significa una tasa de respuesta con una proporción estadística aceptable, debido a que el nivel obtenido fue superior al $50 \%$ de la misma sin que se presentara sesgo alguno, toda vez que las organizaciones que contestaron en nada difieren de manera sustantiva de las que no lo hicieron, en virtud de que al igual que estas últimas están diversificadas en su tipo y que la falta de respuesta exhibida correspondió a un comportamiento natural atribuible básicamente a una excesiva carga de trabajo. Otra opción significativa como criterio de selección de las organizaciones, pero que está ausente del estudio en cuestión, debido a que no forma parte del propósito del mismo, es la que se refiere al hecho de que se pudo haber trabajado sobre la base de una selección de organizaciones prestamistas a partir del número de clientes o socios que tienen, del monto de sus activos, del capital que manejan, de la cartera de crédito vigente y de la rentabilidad, entre otros rubros.

Los elementos que sirvieron de soporte y a su vez como criterio de definición para la selección de las organizaciones prestamistas, fundamentalmente fueron su naturaleza o perfil jurídico, el estatus de autorización ante la respectiva Ley que a cada una les aplica, la filosofía de su funcionamiento, el

7.- Se consideran entidades formales aquellas que están autorizadas por el Gobierno Federal a través de la CNBV para operar conforme a las disposiciones legales existentes; mientras que las entidades no formales son todo lo contrario, aunque algunas todavía a principios del año 2014 se encontraban en proceso de aprobación. 
origen de su conformación, el tipo de productos financieros que ofrecen a la población y el prototipo de prestatario al que va dirigida su atención. Para obtener la información sobre las estructuras contractuales entre las instituciones del sector financiero popular y los prestatarios se aplicó una encuesta al personal responsable del manejo de los créditos en dichas organizaciones. Cabe destacar que para fines del estudio, se guarda confidencialidad del nombre de las organizaciones por su diversidad, objetividad en la información, así como por respeto a su funcionamiento y operación.

El levantamiento de los datos se realizó en tres etapas: una etapa de escritorio, otra de contacto y finalmente otra de aplicación de una encuesta. La primera permitió el desarrollo metodológico de los trabajos sobre la identificación de los instrumentos y las variables objeto del estudio, diseño de formatos y la preparación de oficios tanto de respaldo de la institución como de requerimientos del tipo de información en la que se originan los trabajos de la investigación, orientada a brindar confiabilidad y certeza de la seriedad del proyecto como fase preparatoria para entablar comunicación con los interlocutores.

La etapa de contacto, se realizó bajo dos momentos, la de inicio en la que se realizó el vínculo con las instituciones prestamistas por medio de oficio, explicando el propósito y bondades de la investigación para beneficio del sector de las organizaciones de las finanzas populares, solicitando el acceso y las facilidades para obtener de cada una de ellas ejemplos de 30 contratos de crédito generados durante el año 2013; el segundo momento que fue de repetición con oficio en mano mediante visita directa y acercamiento con el personal gerencial para insistir en la conveniencia de facilitar la información para llevar a cabo el estudio. Como resultado de esta etapa sólo tres del total de los casos respondió y con rechazo, luego de la consulta que efectuaron a sus órganos de dirección, de manera que el resto no respondió.

La etapa de aplicación de la encuesta, mediante la que se logró el contacto directo con los responsables del manejo de los créditos, favoreció la puesta en práctica de un procedimiento recurrente y sistemático, haciendo visitas a las instalaciones de las instituciones seleccionadas como mecanismo que permitió captar la información.

Cabe destacar que lo deseable hubiera sido contar con la oportunidad de acceder de manera directa a los contratos individuales de cada una de las organizaciones de las finanzas populares consideradas, de tal suerte que el ejercicio permitiera extraer una mayor y mejor calidad de la información a fin de establecer las variables totalmente apegadas a la realidad intrínseca de su contenido. Ante la problemática de no disponer de esta opción, hubo que recurrir a realizar encuestas sobre el diseño de los contratos financieros, para recoger los datos que permitieran comprender el comportamiento del fenómeno de las asimetrías y los medios que las instituciones utilizan para mitigarlas. En ese sentido, el objetivo de la investigación estuvo enfocado a indagar la relación entre los problemas de la información asimétrica y el diseño de las estructuras contractuales, es decir si para diferentes situaciones corresponde delinear diferentes tipos de mecanismos contractuales. En ese sentido, se tuvo que pensar en las características y modelos de contratos más frecuentes que utilizan las orga- 
nizaciones de las finanzas populares. La solución que se encontró fue el diseño de un procedimiento orientado a configurar una componente situacional que al expresarse bajo un esquema general respondiera a los diferentes niveles de información asimétrica.

A fin de hacer más explícita esta parte, es preciso señalar que la diferenciación de las situaciones incluyeron a las siguientes tres situaciones genéricas:

Situación 1: Crédito para capital de trabajo a una persona física o moral con actividad empresarial (crédito comercial).

Situación 2: Crédito para consumo para una persona física.

Situación 3: Crédito para vivienda a una persona física.

Lo anterior se explica por el hecho de que en el mercado de los créditos, en el sector de las finanzas populares, las tres modalidades de crédito señaladas, es decir, crédito comercial, crédito al consumo y crédito a la vivienda, son el destino que más comúnmente le dan los prestatarios y ocurre con mayor frecuencia como se puede constatar en la información contenida en los diferentes boletines estadísticos que presenta en su página la CNBV (Comisión Nacional Bancaria y de Valores, 2013).

Los cuatro elementos aplicables desde el enfoque teórico que se combinan con cada uno de los tres tipos de situación mencionados son los siguientes:

Variante A: Hombre, sin antecedentes de deuda y sin comprobante de ingresos.

Variante B: Mujer, sin antecedentes de deuda y sin comprobante de ingresos.

Variante C: Hombre, con antecedentes de deuda y con comprobante de ingresos.

Variante D: Mujer, con antecedentes de deuda y con comprobante de ingresos.

Por lo que se refiere a los elementos hombre y mujer, se consideró la diferenciación debido a que en el mercado de las finanzas populares, la teoría concede gran importancia en el hecho de atender la demanda de servicios financieros tanto del hombre como de la mujer en igualdad de condiciones. No obstante, la experiencia ha demostrado que cuando estas asignan los créditos a la mujer con iniciativas de proyectos productivos, los resultados encontrados han sido más satisfactorios. En las últimas décadas ha proliferado el surgimiento de organizaciones de esta naturaleza que otorgan gran prioridad al otorgamiento del crédito a la mujer, desde la experiencia del Grameen Bank en Bangladesh, Pro Mujer en Bolivia y en México; existen programas del Gobierno Federal como el Fondo de Microfinanciamiento a Mujeres Rurales (FOMMUR) que en el 2013 de un total de 203,228 beneficiarias en el país, se concedieron créditos en Querétaro a 3,228 mujeres (Secretaría de Economía, s.f., b).

El hombre es el que recibe mayores oportunidades de trabajo remunerado en la sociedad y por lo tanto de acceso al crédito; sin embargo, comprometerlos hacia él ofrece condiciones de una más pronunciada información asimétrica, posiblemente debido a factores socioculturales. En la mujer, en su 
calidad de emprendedora de negocios, la problemática de la información asimétrica está aminorada al convertirse en receptora de los créditos y manifestar su capacidad de repago, posiblemente por su mayor sentido de compromiso y agente de cohesión familiar.

En lo referente al antecedente de deuda y la comprobación de los ingresos, son factores que se consideran en el análisis porque constituyen una particularidad muy especial dentro de las finanzas populares, que hacen diferencia respecto al mercado en el que incide la banca tradicional para el otorgamiento de los créditos. Tanto las dificultades asociadas a los antecedentes de deuda como a la comprobación de ingresos, son rubros que se vinculan con el elevado pronunciamiento de la información asimétrica, debido a que por su naturaleza, respectivamente, se propicia incertidumbre en el repago de los créditos y se le relaciona con la falta de capacidad de pago.

Para captar la información en los términos de dicho esquema, se habilitó la herramienta de la Encuesta Específica de Administración de los Créditos que considera información de tres áreas diferentes: A.- Elementos del préstamo, B.- Características generales del préstamo y C.- Características del prestamista.

A continuación se explican las tres categorías de variables, de las cuales se recolectó información a través de las encuestas:

A.- Elementos del préstamo. Un aspecto sustantivo del estudio es el que comprende el análisis de los mecanismos contractuales que se usan para amortiguar los problemas ocasionados por las asimetrías de la información. Aunque en el presente artículo sólo abordaremos algunas de ellas, dichos elementos objeto de investigación son las metodologías crediticias utilizadas por las organizaciones como el préstamo colectivo, el préstamo individual, el préstamo progresivo, la banca comunal, el monitoreo, los pagos frecuentes y los préstamos vinculados al ahorro, entre otros.

B.- Características generales del préstamo. Estos elementos se refieren a las características generales del préstamo. Se pudo captar la información relativa a la garantía, tasa de interés, el tipo de tasa de interés, el tipo de tasa de referencia y la vigencia del crédito.

C.- Características del prestamista. Los elementos a que hacen referencia las características generales de las organizaciones de las finanzas populares son el perfil jurídico de la institución y su gober-

8.- De acuerdo con la publicación denominada Mujeres y Hombres 2013 que emite el INEGI, en México las mayores oportunidades de trabajo remunerado de 14 y más años de edad están orientadas al hombre con una tasa de participación del $68.2 \%$, mientras que la mujer alcanza el $37.4 \%$, situación que favorece a los primeros en cuanto a oportunidades de crédito. Para reforzar lo anterior, de conformidad con el documento Encuesta Nacional de Competitividad, Fuentes de Financiamiento y Uso de Servicios Financieros de las Empresas. Reporte de Resultados (Comisión Nacional Bancaria y de Valores-Banco Interamericano de Desarrollo, s.f.), de cada 10 empresas grandes el $81 \%$ tienen como dueño a un hombre y en el segmento de las microempresas un $29 \%$ de los propietarios son mujeres. Además, es conveniente considerar el segmento de mercado que atiende los requerimientos crediticios de la mujer, sobre la base de las diferentes experiencias suscitadas en el ámbito de las microfinanzas en diferentes partes del mundo, en el que el más representativo es el que se ha presentado en Bangladesh con el Grameen Bank (Yunus, 1998). 
nabilidad. El propósito de recolectar este tipo de información fue entender si las posibles diferencias entre las metodologías crediticias empleadas no se deben a diferencias en la información asimétrica ni a otras variables de control, sino al mercado que atienden dentro del segmento de los excluidos por la banca tradicional y a la experiencia y objetivos de la misma institución.

Como parte sustantiva del proceso de captación de la información, se puso énfasis en la recolección de los datos correspondientes a las variables tipo A y B para cada una de las situaciones mencionadas por separado. Cabe destacar que se omitió considerar la realización de encuestas a los prestatarios, atendiendo al principio de que el mayor nivel de agregación, confiabilidad, conocimiento y dominio de la información se podría obtener por la vía del principal, a fin de conocer los mecanismos especializados de que se valen para mitigar el fenómeno de las asimetrías y estar en condiciones de evaluar las relaciones contractuales que se establecen entre las partes.

\section{4.- Análisis de la información en el contexto del fenómeno}

A partir de los datos obtenidos de la mencionada Encuesta Específica de Administración de los Créditos, cuyo análisis se realizó con el apoyo del Statistic Package for the Social Sciences (SPSS), se efectuaron diferentes ejercicios para analizar el comportamiento de las variables seleccionadas y de las metodologías que las organizaciones de las finanzas populares utilizan, algunas de las cuales se exponen a continuación, mismas que son susceptibles de contribuir a mitigar los efectos de las asimetrías de la información:

a) Garantías. La aplicación de garantías constituye un instrumento de que se valen las instituciones prestamistas para minimizar el riesgo de impago del prestatario, por lo que constituye un incentivo para que el prestatario se esfuerce en el proyecto, toda vez de que de esta manera evitará perderla. Esto de antemano resuelve el problema de riesgo moral, variante de las asimetrías de la información, aunque también mitiga la selección adversa y el racionamiento del crédito como lo señala la teoría. Un rasgo distintivo de las organizaciones de finanzas populares, en general, a diferencia de los bancos comerciales, suele ser la poca o nula aplicación de garantías al momento de otorgar el préstamo, particularmente porque orienta su actividad crediticia a un tipo de población desprotegida financieramente y de muy reducidos o nulos activos.

Por el contrario a lo que la teoría indica, de acuerdo con la información procesada, un hallazgo importante fue que de las 16 organizaciones de las finanzas populares en estudio, 15 exigen garantías como condición para brindar los préstamos, es decir sólo una de ellas no lo hace (Anexo 1, Tabla 
1). De ellas, 5 condicionan el otorgamiento del préstamo a la exigencia de una garantía en una proporción cuyo valor debe ser superior en una relación de 2 a 1 del valor del crédito y para determinadas situaciones hasta de 3 a 1, mientras que 6 lo hacen en una relación de 1 a 1, las restantes no reportan.

Al considerar el tipo de garantía, se observa que el modo más comúnmente usado con el 33.3\% de los casos es el de la combinación de garantías hipotecaria, prendaria, aval solidario y otra (frecuentemente es la garantía líquida) ${ }^{9}$; enseguida con el $10.4 \%$ lo ocupa la modalidad de aval solidario. Esto podría interpretarse como una señal de que las instituciones por todos los medios buscan asegurar la recuperación de los créditos más una ganancia.

En consonancia con lo que señala la teoría, del conjunto de organizaciones prestamistas en estudio, la institución que no está exigiendo garantías, se dirige hacia estratos de población urbana y semi urbana más desprotegidos económicamente (trabajadoras de servicio doméstico, vendedores del pequeño comercio informal, taxistas, albañiles, estudiantes, entre otros).

Adicionalmente, la correlación entre el tipo de garantía y el tipo de tasa de interés resulta ser de -0.240 significativa al 0.01 . Esto significa que se está presentando una relación inversa entre las variables, esperando que al aumentar el monto de la garantía deba bajar la tasa de interés o viceversa, en la proporción resultante. Queda latente para la posterioridad, la idea de corroborar esta afirmación mediante el apoyo de una serie de datos temporales, que permitan analizarlo y determinar hasta donde se cumple este comportamiento (Anexo 1, Tabla 4).

b) Préstamo vinculado al ahorro. El depósito de ahorro en sus diferentes modalidades por parte del prestatario u otros particulares constituye una fórmula de capitalización que da fortaleza a las organizaciones de las finanzas populares y que fomenta el círculo virtuoso del ahorro-crédito y crédito-ahorro, dando pie al préstamo vinculado al ahorro. Esto significa que cuando las organizaciones optan por usarlo como instrumento, una forma de presionar al prestatario a revelar información más cercana a la realidad de lo que pretende hacer con los recursos de crédito y a responder por el repago, es comprometiéndolo a realizar depósitos de ahorro como condición para ello, ya sea mediante la exigencia de fijarle un porcentaje mínimo a reunir de éste o en su caso del total del depósito sólo concederle un cierto monto de crédito. Esto amortigua los efectos de la información oculta que pudiera producirse en la relación con los intermediarios financieros.

En este renglón, del total de los casos estudiados en las organizaciones, se encontró que en 128 situaciones válidas, el $67.2 \%$ de los préstamos está vinculado al ahorro, mientras que el $32.8 \%$ no lo están. Los que están, son sujetos a un cierto porcentaje que deben reunir como mínimo de ahorro, en

9.- En el conjunto de la información recibida como resultado de la encuesta, se pudo identificar que existen instituciones para las cuales es indistinto que el prestatario, para estar en condiciones de recibir el crédito, tenga como colateral la combinación de garantías, como también las hay que son las menos cuya orientación de mercado se dirige a sectores muy desprotegidos económicamente y que recurren a la opción del aval solidario. 
ocasiones del $10 \%$ y hasta del $20 \%$, como requisito para acceder al crédito en su calidad de garantía de acuerdo con las condiciones que fija la institución prestamista al prestatario (Anexo 1, Tabla 5). Aunque en menor medida, sobreviene también la alternativa de la pignoración que opera para otorgar el crédito como un porcentaje del depósito existente, modalidad que podría ser considerada como ahorro obligatorio y que de acuerdo con la teoría es la menos exitosa si se trata de aminorar las asimetrías de la información, a diferencia del ahorro voluntario que induce a los prestatarios a revelar las habilidades de sus proyectos en una situación de riesgo moral cuando el crédito se orienta a proyectos productivos (Olivier, 2011).

c) Préstamo colectivo. Por sus características esta metodología tiene la virtud de estimular entre los prestatarios los aspectos de identificación, control y cumplimiento de los contratos. Igualmente reduce 0 elimina los costos de agencia de la entidad crediticia, esquema que se facilita porque mantiene informados a unos sobre otros de los integrantes del grupo, permite la recomendación para la incorporación de nuevos prestatarios, se ve favorecida por la proximidad geográfica y fortaleza de los vínculos sociales de los integrantes haciendo de esto en cierto sentido la creación del denominado capital social. Estos factores mitigan los efectos de la información asimétrica debido al mayor conocimiento que se adquiere sobre las características de los prestatarios, lo que propicia la confianza y las mayores posibilidades de éxito de las organizaciones de las finanzas populares.

Aunque se le relaciona con más ventajas, existen estudios relativamente recientes como los realizados por Sharma and Zeller (1997), que señalan que una de las desventajas de esta metodología es que propicia un aumento en los problemas de pago cuando la conformación mayoritaria está integrada por familiares. Esta forma de operar tendría una debilidad si se constituyen por sectores de población heterogéneos y sin sentido de la solidaridad ${ }^{10}$.

Del conjunto de las experiencias estudiadas a nivel situacional, en la práctica la metodología del préstamo colectivo sólo se ve reflejada en el $15.6 \%$ de los casos, los restantes $84.4 \%$ de éstos corresponde a la aplicación de otras metodologías. Del total sólo 3 organizaciones utilizan esta metodología. Esto constituye un hallazgo que exhibe el desconocimiento que poseen las organizaciones sobre las bondades que tiene la metodología de responsabilidad colectiva o de préstamos colectivos por encima de la de préstamos individuales como se describe en el modelo expuesto en el apartado sobre la perspectiva teórica de las asimetrías de la información (Anexo 6).

d) Banca comunal. Se conforman por grupos de 20 a 50 personas o más, conocidos entre sí, que se distinguen por ser buenos pagadores y con la voluntad de responder por el incumplimiento de integrantes no pagadores. Un $20 \%$ de lo prestado se compromete como ahorro. Se le relaciona más con las garantías morales y solidarias, a la vez que suele aplicarse en grupos de mujeres, lo

10.- La heterogeneidad económica, social y cultural y su influencia en la formación de grupos sociales organizados y en particular del llamado capital social, han sido objeto de estudio de manera empírica, por ejemplo en algunas ciudades de Estados Unidos. Al respecto, se ha encontrado que la existencia de este factor representa enormes dificultades en la constitución de los grupos (Alesina and La Ferrara, 1999). 
que favorece la mitigación de los efectos de cualquier actitud de ocultamiento de la información ${ }^{11}$. A nivel situacional, del análisis efectuado, un $10.9 \%$ de los casos son aplicados por la metodología de bancos comunales y la ponen en práctica sólo 3 organizaciones de las finanzas populares (Anexo $6)$.

e) Préstamo individual. Para fines del ámbito en que inciden las organizaciones de las finanzas populares, estas se apoyan en la exigencia de un plan de negocios y/o en la capacidad y voluntad de pago del prestatario. De acuerdo con las mejores prácticas, llega a ser exitoso siempre que las organizaciones de las finanzas populares cuenten con una larga experiencia y conocimiento de sus clientes 0 socios. Esta tecnología es la más comúnmente utilizada por la banca tradicional y es considerada de altos costos.

La metodología de préstamo individual es la más frecuentemente esgrimida por las organizaciones con el $90.6 \%$ de los casos a nivel situacional. Al respecto, sólo 2 de las organizaciones de finanzas populares no manejan esta metodología, toda vez que una se enfoca a la metodología de préstamo colectivo y la otra a la de banca comunal (Anexo 6).

f) Monitoreo. Es una metodología que las instituciones emplean al momento de asignar los créditos, para investigar la solvencia del cliente o socio a través de las empresas denominadas Buro de Crédito que tienen como actividad recopilar, manejar y entregar a las instituciones prestamistas el historial crediticio de los prestatarios. Pocas organizaciones aprovechan la herramienta del monitoreo a través del apoyo de los propios prestatarios para realizar la supervisión ex ante y ex post, entre sí, a la entrega del crédito, a pesar de que podría ser una vía sin costos y en el que la información que se obtenga puede ser de mejor calidad sobre el riesgo del crédito e incluso sobre el destino del crédito. A través de ella se previenen las manifestaciones de la selección adversa y riesgo moral.

Como mera fiscalización, mediante visitas a domicilio y a través de estos buró, está presente la metodología de monitoreo en el $87.5 \%$ de las situaciones que fueron escenificadas al principio de este apartado y que se pone en práctica a través de 14 instituciones prestamistas. En las organizaciones de finanzas populares del Municipio de Querétaro, se recurre a la participación de clientes y socios en calidad de supervisores básicamente cuando aplican la tecnología de banca comunal y de préstamo colectivo (Anexo 6).

g) Pagos frecuentes. Esta modalidad constituye una metodología crediticia de que se valen las organizaciones de finanzas populares y que generalmente las hace diferentes respecto de la banca tradicional en sus métodos de cobranza con los prestatarios. Los pagos frecuentes van asociados generalmente a montos pequeños y pagos semanales o de menos días.

11.- Esta metodología se basa en el modelo creado por la Fundación para la Asistencia Comunitaria Internacional (FINCA) descrito en el Manual de Bancos Comunales (Keith and Hatch, 1989). En el plano teórico está dirigido a crear una base de activos en aquellos sectores de población considerados como los más pobres de los pobres. 
Existen instituciones que tienen dentro de su mecánica de trabajo otorgar prioridad a la cobranza como fórmula para impedir el problema de los elevados índices de cartera vencida. Para ello, habilitan la figura de los oficiales de crédito, que tienen entre otras tareas no sólo promover la colocación del crédito, sino en gran medida realizar visitas semanales a los hogares de los prestatarios para efectos de cobro. Otra opción que utilizan para que los prestatarios efectúen pagos frecuentes consiste en adoptar formas de organización bajo la figura de comités o grupos, de tal manera que por el efecto de las distancias y de la confiabilidad, el prestatario más cercano a las oficinas de la institución se responsabiliza de entregarle a ésta el monto del pago semanal recolectado que corresponde a los deudores. Ahí donde esta alternativa es aplicada por las organizaciones prestamistas, se logran fortalecer los lazos de los agentes económicos de la intermediación financiera, se favorece la confianza y el flujo de la información, así como también se propicia la incorporación de prestatarios responsables, lo que contribuye en suma a minimizar los efectos de la información asimétrica.

Derivado del análisis, se encontró que debiendo ser la alternativa de pagos frecuentes las erogaciones semanales por parte del prestatario, como suele suceder en este tipo de organizaciones, resulta que no es así. Lo que predomina realmente es la opción de pago mensual con el $64.8 \%$ como ocurre con la banca comercial, quedando en segundo lugar el pago semanal con el 10.9\%. Los resultados arrojaron la idea de una combinación de pagos mensuales, quincenales o semanales con un $36.7 \%$, porcentaje contenido dentro del resultado mensual, derivado de respuestas un tanto informales, proporcionadas por los representantes de las instituciones prestamistas, en el sentido de que el prestatario al menos debe asegurar sus pagos mensuales y si es su voluntad lo pueden hacer de manera quincenal o semanal quedando a su criterio y capacidad de pago (Anexo 6).

De la información revisada, se desprende que esta metodología tiene poca aplicación por las organizaciones de las finanzas populares en el Municipio de Querétaro, al estar representados los pagos semanales sólo con el $10.9 \%$ de las que lo aplican y al manifestarse con nula presencia los pagos más frecuentes, es decir los que son menores a una semana. La experiencia que se presenta, difiere de otras que se han estudiado en otros países, en el sentido de que al emplearse la figura de los pagos frecuentes facilita a la institución la acción de mitigar las consecuencias de la información asimétrica, por el efecto formativo y de disciplina financiera que propicia sobre el prestatario después de recibir el recurso de crédito, en virtud de que genera el hábito de la responsabilidad de pago en forma más continua y permanente. De esta manera se fomenta una cultura de pago muy sólida, toda vez que se afianza la comunicación y se genera un flujo de la información más terso entre la institución y el pres$\operatorname{tatario}^{12}$.

12.- Investigaciones realizadas sobre los pagos frecuentes como opción para mitigar las asimetrías de la información, los relacionan con el fomento de la disciplina financiera, los costos de transacción y la existencia de prestamistas informales (Jain and Mansuri, 2003); otros profundizan en experiencias vinculadas con el monto de los préstamos, los costos de transacción, el nivel de ingresos de la población que se atiende y el monitoreo sobre la capacidad de pago (Armendariz y Morduch, 2011).

CIRIEC-España, Revista de Economía Pública, Social y Cooperativa ISSN: 0213-8093 
h) Préstamo progresivo. De acuerdo con el estudio realizado, en la práctica, esta metodología tiene una connotación hasta cierto punto trivial. Esto obedece al hecho de que cuando es ejecutada por las instituciones se considera como algo implícito y natural que el crédito sea progresivo conforme al historial crediticio del cliente 0 socio.

La sistematización del crédito progresivo que está presente a nivel situacional en el $93.8 \%$ de los casos, se maneja de una manera tácita por parte de las instituciones a modo de incentivo para el prestatario, lo que favorece también a la organización prestamista porque le proporciona información real sobre la capacidad de respuesta del prestatario y propicia la mitigación del riesgo moral (Anexo $6)$.

\section{5.- Discusión de los resultados}

El estudio de las estructuras contractuales en el sector de las finanzas populares en el Municipio de Querétaro en un contexto de información asimétrica, es un tema de investigación relevante en el ámbito de la economía y las finanzas en general por lo que representan, por el tipo de mercado que atienden y por ser de actualidad en las ciencias económicas. En él se recogen y procesan las aportaciones de diferentes investigaciones sobre los instrumentos y metodologías utilizadas en las finanzas populares, de manera que al abordarlo desde la perspectiva de la microeconomía y particularmente de la teoría de contratos, los resultados obtenidos permiten sentar las bases para explorar más a fondo a otras vertientes de actividad como por ejemplo la gobernanza y su incidencia en el fenómeno.

En ese sentido, se ha considerado relevante destacar algunos aspectos generales encontrados como resultado del estudio realizado y que a continuación se señalan:

i) Las organizaciones de las finanzas populares son instituciones cuyo perfil pueden estar o no reconocidas dentro del marco legal existente ya mencionado y por consiguiente de la vigilancia directa o indirecta de la CNBV a través de las vías de que dispone para ello. Atienden a una población mayoritariamente de escasos recursos y en su caso están abiertas a considerar a personas de clase media. Pueden tener un enfoque mixto de orientación, es decir están enfocadas a hombres y mujeres y en pocos casos preferentemente a mujeres. Sus instalaciones se encuentran ubicadas en el Municipio de Querétaro aunque la mayoría de ellas suelen tener un radio de acción mayor al estar presentes en otros municipios del Estado de Querétaro o inclusive con presencia en otros estados y países. 
Las organizaciones objeto de estudio son de naturaleza jurídica diversa. Esto es, las sociedades financieras populares bajo la modalidad de sociedades anónimas y las sociedades cooperativas de ahorro y préstamo con facultades para captar ahorro de la población y otorgar préstamos ${ }^{13}$. Las sociedades cooperativas de consumo sin la atribución para captar depósitos y con un peso importante para otorgar préstamos. Las sociedades financieras de objeto múltiple que ofrecen productos crediticios y realizan operaciones de arrendamiento y factoraje, mismas que se fondean de instituciones financieras y/o emisiones públicas de deuda. Muy excepcionalmente está incluida una institución de banca múltiple cuya actuación se inscribe en el marco de la Ley de Instituciones de Crédito y cuyo mercado son las microfinanzas ${ }^{14}$. Adicionalmente, está presente en el estudio un caso especial que nace como brazo operativo y financiero de la banca comercial y que está abocado exclusivamente al sector popular adoptando los esquemas de colocación de los créditos de estas organizaciones.

En otro tenor, en cuanto a la antigüedad de las instituciones, para conocer hasta dónde la experiencia está presente en el grado de influencia en la información captada, se encontró que 4 instituciones tienen más de 50 años operando, 2 lo hacen con más de 40 años, 4 tienen más de 15 años y 6 están entre 4 y 10 años de vida trabajando. A manera de reflexión, se consideró la variedad y condiciones de los servicios que ofrecen las organizaciones como factor fundamental, toda vez que se previó como susceptible de arrojar información valiosa respecto del grado de presencia en el mercado objeto de estudio y de los sectores de población que se atiende, aunque de algún modo también para apreciar el comportamiento del prestatario a la luz del fenómeno de las asimetrías de la información.

ii) De acuerdo con la información que estiman las organizaciones de finanzas populares de Querétaro y que informalmente nos fue transmitida, en el segmento del mercado de intermediación financiera que atienden y que corresponde a los excluidos de la banca tradicional, el $70 \%$ de los créditos son para consumo, el $25 \%$ para crédito comercial y el $5 \%$ para crédito para la vivienda ${ }^{15}$, es decir se corrobora que existe una fuerte carga de información asimétrica, máxime cuando manifiestan poco interés por dar seguimiento al destino del crédito y al desprecio por diferenciar adecuadamente el crédito comercial del crédito al consumo. Cabe señalar que la demanda de crédito para la vivienda es

13.- De acuerdo con la Ley para Regular las Actividades de las Sociedades Cooperativas de Ahorro y Préstamo en su artículo 2, Fracción $X$, se concibe a las sociedades cooperativas de ahorro y préstamo como "...sociedades constituidas y organizadas conforme a la Ley General de Sociedades Cooperativas, independientemente del nombre comercial, razón o denominación social que adopten, que tengan por objeto realizar operaciones de ahorro y préstamo con sus Socios, y quienes forman parte del sistema financiero mexicano con el carácter de integrantes del sector social sin ánimo especulativo y reconociendo que no son intermediarios financieros con fines de lucro".

14.- Durante aproximadamente las últimas dos décadas del siglo pasado, en México el concepto de microfinanzas aplicó para aquellas instituciones que fundamentalmente basaban su funcionamiento en el otorgamiento de productos de crédito dirigidos a sectores de población económicamente desprotegidos y a ciudadanos con niveles de ingreso medio bajo, que tenían como base el fondeo de recursos provenientes de otras instituciones financieras como las bancarias toda vez que no captaban ahorro. Con la aprobación de la LACP, esta situación cambió predominantemente para aquellas microfinancieras que fueron autorizadas debido a que se convirtieron en sociedades financieras populares con facultades para ahorrar, mientras que las que incumplieron con los requisitos exigidos se limitan a operar productos de crédito como en el pasado, es decir sin estar basados en el ahorro.

15. - Particularmente por lo que se refiere a la cartera de crédito vigente de las sociedades cooperativas de ahorro y préstamo, la composición es del $84.2 \%$ para crédito al consumo, $9.3 \%$ para crédito comercial, $0.1 \%$ para microcréditos y $6.4 \%$ para crédito a la vivienda (Comisión Nacional Bancaria y de Valores, 2013).

CIRIEC-España, Revista de Economía Pública, Social y Cooperativa ISSN: 0213-8093

№ $84 / 2015$, pp. 133-162 
atendida por las instituciones prestamistas, generalmente con recursos provenientes de programas de gobierno, bajo los términos y condiciones previamente establecidos por éste, esto es entre otras consideraciones en cuanto a monto, tasa de interés y vigencia del crédito.

iii) Las organizaciones de las finanzas populares incorporan instrumentos y metodologías crediticias especializadas que se ajustan a las características del mercado que atienden, cuyas condiciones son complejas y de elevados costos, lo que les permite suavizar las consecuencias que se derivan de la información asimétrica.

iv) Como parte de dichas herramientas, a diferencia de lo que la teoría indica, estas organizaciones de manera parecida a como lo hacen los bancos, ante la falta de información sobre las características de los prestatarios, para minimizar las asimetrías de la información y asegurar el pago de los créditos, en muchas ocasiones endurecen las medidas que utilizan para prestar el servicio mediante el establecimiento de la exigencia de garantías fundamentalmente reales con montos significativos, así como de tasas de interés con montos elevados.

v) En cuanto a la aplicación de metodologías, se observa que están polarizadas las preferencias, debido a que la gran mayoría de las organizaciones ponen en práctica la tecnología de préstamos individuales al tener amplia superioridad en cuanto a presencia en los casos a nivel situacional; mientras que las metodologías de préstamos colectivo y de banca comunal son escasamente utilizadas a pesar de que están diseñadas para minimizar la información asimétrica en estos espacios. Por lo que se refiere a la experiencia del monitoreo como metodología crediticia, hay preponderancia por recurrir a la opción del buro de crédito para investigar al prestatario con el correspondiente costo, en parte por exigencia de ley y como forma de transparentar la obtención de información, aunque en el mejor de los casos lo hacen a través de la realización de visitas domiciliarias. Esto podría exhibir para las que tienen la posibilidad de hacerlo, de un cierto desconocimiento o falta de interés por innovar para involucrar, sin costo alguno, en esta labor a los propios prestatarios.

A continuación, se pone a consideración, en contexto, para efectos de discusión, entre otros puntos los siguientes:

i) En el mercado de la intermediación financiera, aunado a las condiciones macroeconómicas del país, la falta de aplicación de tecnologías crediticias adecuadas contribuye a que las tasas de interés sean elevadas. Esto castiga cualquier iniciativa de la sociedad, debido a que al no lograr la maduración requerida de sus proyectos productivos obtienen tasas de rentabilidad con un nivel insuficiente para cubrir el costo de la tasa de interés. A su vez, esto coarta el deseo de los grupos e individuos con aspiraciones a desarrollarse en sus respectivos mercados, propiciando que amplios sectores de potenciales prestatarios queden excluidos de los servicios financieros. 
En un contexto de esa naturaleza, bajo condiciones de competencia, las organizaciones del sector de las finanzas populares se ven obligadas a sobrellevar la situación para prevalecer en el mercado, de manera que al no lograr atenuar suficientemente los efectos de las asimetrías mediante la aplicación de las metodologías crediticias adecuadas, se ven obligadas a trabajar con elevadas tasas de interés para asegurar en el tiempo la recuperación de los créditos. Tan sólo las organizaciones objeto de estudio ofrecen tasas de interés mínimas que oscilan desde el 10\% al 264\% anual, de manera que la tasa de interés mínima promedio que arrojan 128 situaciones válidas es del 37.25\% (Anexo 1, Tablas 1 y 3). Del total de las 16 organizaciones prestamistas seleccionadas, por debajo de dicho promedio en la tasa de interés se ubican a 10 de ellas con tasas que oscilan del 10 al 32\%, las restantes 6 están por arriba con tasas del 42 al 264\%. En forma ordinaria, la tasa de interés más frecuentemente utilizada con un $15.6 \%$ de los casos por las instituciones prestamistas es la del 19\%, enseguida con un $9.4 \%$ es la tasa del $30 \%$ y en tercer lugar con el $6.3 \%$ de frecuencia se utilizan 8 tasas que van desde el $10 \%$ hasta el $93 \%$ para créditos comerciales y de consumo.

Por otra parte, en cuanto al tipo de tasa de interés para los préstamos, en el mercado de las organizaciones financieras populares consideradas, prevalece la tasa fija con el $81.3 \%$ de los casos y con el restante $18.7 \%$ opera con la tasa variable. Esta situación se atribuye a la certeza que requieren el tipo de prestatarios que conforman el mercado para efectos de asegurar el repago, es decir es una población susceptible de minimizar riesgos. La tasa de referencia en la que se basan los créditos otorgados predominantemente descansan en un $55.1 \%$ de los casos en los CETES, un $20.4 \%$ en otros y un 12.2 en la TIIE (Anexo 1, Tabla 3).

ii) En el ámbito urbano y semiurbano del Municipio de Querétaro en la que se realiza el estudio, un aspecto singular de la relación prestamista-prestatario se enmarca bajo condiciones de heterogeneidad en la composición de los prestatarios, de competencia atribuible a la gama de instituciones que prestan, así como de calidad en el servicio relacionada con los productos que ofrecen y la oportunidad que tienen en la respuesta para otorgar los créditos, situación que favorece la presencia del fenómeno de la información asimétrica.

iii) La banca comercial ha identificado la idea de negocio que existe en los mercados de intermediación financiera que atienden las organizaciones de las finanzas populares y empieza a tener presencia a través de organismos especializados en esquemas microfinancieros, experiencia que se vive en este tipo de mercados desde hace un par de lustros en países del cono sur. Algunas instituciones bancarias como Banco Azteca y cadenas comerciales como Walmart, Famsa y Coppel, lo vienen haciendo. Se tiene conocimiento que otras lo realizan a través de la colocación de financiamiento en instituciones microfinancieras para que a su vez lo administren como cartera crediticia. 


\section{6.- Conclusiones}

Como resultado del análisis efectuado sobre las estructuras contractuales en el mercado de las finanzas populares, en condiciones de información asimétrica, en el Municipio de Querétaro, México, conviene destacar algunos hechos relevantes:

i) Se pone al descubierto que, a diferencia de lo que abordan las predicciones teóricas de la economía de la información, específicamente de la economía de las finanzas populares, las organizaciones que operan en el mercado que atiende a los excluidos por la banca comercial, predominantemente conceden préstamos a la población objetivo exigiéndole como requisito la entrega de garantías, al mismo tiempo que generalmente lo hacen bajo condiciones de aplicación de tasas de interés elevadas. Esto indica que lo que buscan es fortalecer los mecanismos de recuperación de los créditos para resguardarse rentablemente, lo que hace suponer que el propósito social no es una de sus prioridades. Para las instituciones, es el camino que han encontrado para mantenerse competitivas, aminorando riesgos y en su caso suavizando los efectos de las asimetrías de la información. A reserva de realizar un análisis más profundo, esto podría atribuirse a dos factores fundamentales, por una parte a la fuerte carga de información asimétrica en que se desenvuelve la actividad de la intermediación financiera en un segmento del mercado con características urbanas y semiurbanas, en la que prevalece una intensa competencia entre las organizaciones prestamistas, y por la otra, a que dichas instituciones proporcionan servicios financieros dirigidos a brindar atención a una población prestataria presumiblemente muy heterogénea en su composición y con elevado riesgo en la capacidad de respuesta para el repago de los créditos.

ii) No obstante la diversidad de alternativas en las metodologías crediticias con que trabajan las organizaciones de las finanzas populares, en un mercado que se distingue por su complejidad y altos costos para obtener la información correspondiente a los prestatarios, para aminorar las asimetrías de la información dichas organizaciones recurren primordialmente a la alternativa de préstamos individuales, acompañada del recurso del buró de crédito, tal y como lo hacen los bancos tradicionales. Esto debiera presuponer un conocimiento muy cercano del prestatario, no obstante su heterogeneidad.

iii) El fenómeno de las asimetrías de la información en las condiciones en que se presenta y bajo la forma en que se atenúan sus efectos, presupone también la existencia de un amplio sector de población que continúa excluido de los servicios financieros, aspecto que ameritaría futuras indagaciones. 
iv) Frente a lo que se había previsto a nivel situacional, como resultado de la evaluación, se pudo constatar que las metodologías crediticias se aplican por igual a hombres y mujeres, excepto en aquellos casos de tipo grupal que en contadas instituciones marcan una tendencia orientada a trabajar con la mujer en el mercado de la colocación de los créditos, aspecto que de intensificarse favorecería en la mitigación de los efectos del fenómeno de las asimetrías de la información. En cuanto a la gobernanza se abre la posibilidad de un campo de estudio importante sobre las organizaciones del sector de las finanzas populares, que permita identificar cómo inciden sus estructuras de gobierno, la toma de decisiones y la naturaleza jurídica de las organizaciones en la mitigación de la información asimétrica.

v) A pesar de la fuerte carga de información asimétrica en el mercado de intermediación financiera, particularmente en el mercado de los excluidos, es factible que la banca comercial en un futuro ahonde en su interés por penetrar en dicho espacio bajo diversas modalidades, máxime que han observado que es un gran segmento de oportunidad de negocio. El hecho de que los prestatarios manifiesten capacidad de respuesta ante préstamos con exigencias de garantías y elevadas tasas de interés, son señales claras que reafirman la posibilidad de que la banca tradicional aumente su inquietud para ingresar en él. Esto les implicará retomar algunas metodologías crediticias que utilizan las organizaciones del sector financiero popular bajo ciertas adaptaciones que favorezcan su actividad.

Finalmente, a partir del conjunto de elementos abordados, se puede afirmar que se acepta la hipótesis establecida según la cual las organizaciones del sector financiero popular en el Municipio de Querétaro utilizan estructuras contractuales de crédito especializadas para ajustarse a las características del mercado que atienden. En tal sentido, es indudable que la actividad que realizan las organizaciones de las finanzas populares en el Municipio de Querétaro con el apoyo de las metodologías e instrumentos que utilizan, logran generar estructuras contractuales que mitigan los efectos de una pronunciada información asimétrica en un mercado en el que la exclusión de servicios financieros impide el mejoramiento de las condiciones de vida de determinados sectores de población. La presencia de las organizaciones se inscribe en una especie de etapa de transición donde la prioridad se orienta a ganar el mercado de los estratos medios de la población que se ubica en la base de la pirámide de la intermediación financiera, sustentándose en la sostenibilidad financiera, aunque también tienen como reto continuar trabajando para lograr su total formalización ante la ley cuando tienen la obligatoriedad de hacerlo. Sin embargo, queda la percepción de que éstas predominantemente están dejando en segundo plano su orientación social.

Están a la vista los elementos relevantes que pudieran retroalimentar las estructuras contractuales para generar condiciones óptimas en la relación prestamista-prestatario, de tal suerte que favorezca a las organizaciones de las finanzas populares ampliar su presencia en dicho mercado, se coadyuve a reducir las tasas de interés, se atenúen en mayor medida los efectos del fenómeno de las asimetrías de la información y se contribuya a la inclusión financiera de los excluidos por la banca comercial. 


\section{7.- Bibliografía}

AKERLOF, M. (1970): "The Market for 'Lemons': Quality Uncertainty and the Market Mechanism”, The Quarterly Journal of Economics, 84 (3), 488-500.

ALESINA, A. \& LA FERRARA, E. (1999): "Participation in Heterogeneous Communities", Nber Working Paper Series, National Bureau of Economic Research. Working paper 7155. Recuperado de http://www.nber.org/papers/w7155.pdf.

ARMENDÁRIZ, B. \& MORDUCH, J. (2011): Economía de las Microfinanzas, Fondo de Cultura Económica-Centro de Investigación y Docencia Económicas, A.C. Primera edición en español de la segunda en inglés, México, D.F.

ASOCIACIÓN DE BANCOS DE MÉXICO (2010): Indicadores Económicos y Financieros.

Recuperado de: www.condusef.gob.mx/PDF-

s/cuadros_comparativos/articulos_interes/indicadores_abm_febrero10.pdf.

BERGUER, M., OTERO, M., SCHOR, G., MARULANDA, B., ROSALES, R., MURIEL, A., MURIEL, V., FRANCO, G., MARTÍN, E., CASTELLO, S., DANEL, C., GOLDMARK, L., PECK, R., MILLER, J. \& MILLER, T.-SANABRIA (s/f): El boom de las microfinanzas. El modelo latinoamericano visto desde adentro, Banco Interamericano de Desarrollo. Recuperado de: www.risalc.org/portal/publicaciones/ficha/?id=1532.

CAMPOS, B. (2005): El Ahorro Popular en México: Acumulando Activos para Superar la Pobreza, $1^{\mathrm{a}}$ ed. México, D.F: Editorial Miguel Ángel Porrúa.

COMISIÓN NACIONAL BANCARIA Y DE VALORES (2013): Boletín Estadístico 2013. Recuperado de http://portafoliodeinformacion.cnbv.gob.mx/eacp1/Paginas/boletines.aspx.

COMISIÓN NACIONAL BANCARIA Y DE VALORES (s.f., a): Descripción del Sector. Recuperado de http://www.cnbv.gob.mx/SECTORES-SUPERVISADOS/SECTOR-POPULAR/Descripci\%C3\%B3ndel-sector/Paginas/default.aspx.

COMISIÓN NACIONAL BANCARIA Y DE VALORES (s.f., b): Glosario de Términos Portafolio de Información. Recuperado de

http://portafolioinfdoctos.cnbv.gob.mx/Documentacion/minfo/00_DOC_R1.pdf.

COMISIÓN NACIONAL BANCARIA Y DE VALORES-BANCO INTERAMERICANO DE DESARROLLO (s.f.): Encuesta Nacional de Competitividad, Fuentes de Financiamiento y Uso de Servicios Financieros de las Empresas. Reporte de Resultados. Recuperado de http://www.cnbv.gob.mx/Prensa/Estudios/Reporte\%20de\%20la\%20ENAFIN.pdf. 
CONDE, C. (2005): Instituciones e Instrumentos de las Microfinanzas en México. Definamos términos, El Colegio Mexiquense, A.C., Programa Interdisciplinario de Estudios del Tercer Sector.

CONDUSEF (2011): Comisión Nacional para la Protección y Defensa de los Usuarios de Servicios Financieros, http://www.condusef.gob.mx.

COMPARTAMOS BANCO (2010): Informe Anual y Sustentable. Recuperado de: www.comparta$\mathrm{mos} . \mathrm{com} / \mathrm{wps} /$ portal/Documentos.

EGLI, D. (2004): "Progressive Lending as an Enforcement Mechanism in Microfinance Programs", Review of Development Economics, 8(4), 505-520.

FISCHER, G. \& GATHAK, M. (2010): Repayment Frequency in Microfinance Contracts with PresentBiased Borrowers, London School of Economics, recuperado de http://econ.Ise.ac.uk/staff/mghatak/My\%20Papers/frequentFG.pdf.

GAVITO, J. (2005): "Fortalecimiento y Desarrollo de las Finanzas Populares en México", Revistas ICE, 821, 213-224. Recuperado de: http://www.revistasice.com/CachePDF/ICE_821_213224_C6FD001F0D7B14B07DB0A56B40DC7EAE.pdf .

GONZÁLEZ, C. \& ALPIZAR, C. (2006): Los Mercados de las Finanzas Rurales y Populares en México: Una Visión Global Rápida sobre su Multiplicidad y Alcance. El Sector de las Microfinanzas en México, United States Agency International Development, México. Recuperado de http://cideosu.cide.edu/Sample\%20Website/pagina\%20web/3.Documentos/Afirma\%20V\%20\%20Sector\%20de\%20Microfinanzas.pdf.

HART, O. (2001): "Financial Contracting", Journal of Economic Literature, 39 (4), 1079-1100.

HELMANN, T. \& STIGLITZ, J. (2000): "Credit and equity rationing in markets with adverse selection", European Economic Review, 44, 281-304. Recuperado de: https://www0.gsb.columbia.edu/faculty/jstiglitz/download/2000_Credit_and_Equity_Rationing_in_Markets.pdf.

IMPERIAL, R. \& RAMÍREZ, F. (2001): Banca Social. Historia, Actualidad y Reto de las Finanzas Populares, $1^{a}$ ed. México: Editorial Caja Popular Mexicana.

INSTITUTO NACIONAL DE ESTADÍSTICA Y GEOGRAFÍA (s.f., a): Otras Instituciones de Intermediación Crediticia y Financiera no Bursátil, Directorio Estadístico Nacional de Unidades Económicas. Recuperado de http://www3.inegi.org.mx/sistemas/mapa/denue/default.aspx.

INSTITUTO NACIONAL DE ESTADÍSTICA Y GEOGRAFÍA (s.f., b): Sistema para la consulta del anuario estadístico de Querétaro 2012. Recuperado de: http://www.queretaro.gob.mx/sedesu/contenido.aspx?q=YoMWuRZZIwHbCWd3jU5TT6BQiylgD8dU.

INSTITUTO NACIONAL DE ESTADÍSTICA Y GEOGRAFÍA (2014): Mujeres y Hombres en México 2013. Recuperado de:

http://www.inegi.org.mx/prod_serv/contenidos/espanol/bvinegi/productos/integracion/sociodemo grafico/mujeresyhombres/2013/Myh_2013.pdf. 
JAIN, S. \& MANSURI, G. (2003): "A little at a time: the use of regularly scheduled repayments in microfinance programs", Journal of Development Economics, 72, 253-279. Recuperado de: http://www.researchgate.net/publication/222298882_A_Little_at_a_Time_The_Use_of_Regularl y_Scheduled_Repayments_in_Microfinance_Programs.

KEITH, J. \& HATCH, M. (1989): Manual de Bancos Comunales para Líderes Promotores, FINCA: Alexandria. VA.

LELAND, H. \& PYLE, D. (1977): "Informational Asymmetries, financial structure and Financial Intermediation", The Journal of Finance, 32 (2), 371-87. Recuperado de https:/www2.bc.edu/ chemmanu/phdfincorp/MF891\%20papers/Leland\%20and\%20Pyle\%201975.pdf

MACHO, I. \& PÉREZ, D. (2009): Introducción a la Economía de la Información, Editorial Ariel, Barcelona, España.

MANSELL, C. (1995): Las Finanzas Populares en México. El Redescubrimiento de un Sistema Financiero Olvidado, México. CEMLA, Editorial Milenio, ITAM.

MARTOWIJOYO, S. (s.f.): Las Microfinanzas en Indonesia y el sistema de unidad BRI: Caso del Banco Rakyat, Series Documentos de Trabajo I-40JP. Washington, D.C. Recuperado de http://issuu.com/idb_publications/docs/working_es_10738.

OLIVIER, B. (2011): Compulsory versus Voluntary Savings as Incentive Mechanism in Microlending Contracts, University of Nice Sophia-Antipolis, GREDEG-CNRS SKEMA Business School and OFCE-DRIC, France. Recuperado de http://www.rug.nl/research/globalisation-studiesgroningen/research/conferencesandseminars/conferences/eumicrofinconf2011/papers/1a.khachatryanbruno.pdf.

ORGANIZACIÓN INTERNACIONAL DEL TRABAJO (s.f.): Finanzas sociales. Recuperado de http://www.ilo.org/empent/areas/social-finance/lang--en/index.htm.

PRAHALAD, C.K. (2005): La Fortuna en la Base de la Pirámide. Cómo crear una vida digna y aumentar las opciones mediante el mercado, Ediciones Granica, Barcelona.

ROBINSON, M. (1994): "Savings Mobilization and Microenterprise Finance: The Indonesian Experience". En: Maria Otero and Elizabeth Rhyne, The New World of Microenterprise Finance, West Hartford, Connecticut: Kumarian Press, 27-54.

ROBINSON, M. (2004): La Revolución Microfinanciera: Finanzas Sostenibles para los Pobres, México: Instituto Nacional para el Desarrollo de Capacidades del Sector Rural, A.C.

RODRÍGUEZ, J. (2000): "Group and Individual Microcredit Contracts: A Dynamic Numerical Analysis". Dissertation presented in Partial Fulfillment of the Requirements for the Degree Doctor of Philosophy in the Graduate. School of The Ohio State University. Recuperado de: http://citeseerx.ist.psu.edu/viewdoc/download?doi=10.1.1.332.9432\&rep=rep1\&type=pdf. 
ROTHSCHILD, M. \& STIGLITZ, J. (1976): "Equilibrium in Competitive Insurance Markets: An Essay on the Economics of Imperfect Information", The Quarterly Journal of Economics, 90 (4), 629-649. Recuperado de: http://www.uh.edu/ bsorense/Rothschild\&Stiglitz.pdf.

SECRETARÍA DE ECONOMÍA (s,f., a): ProMéxico. Inversión y Comercio. Recuperado de http://mim.promexico.gob.mx/Documentos/PDF/mim/FE_QUERETARO_vf.pdf.

SECRETARÍA DE ECONOMÍA (s.f., b): Fondo de Microfinanciamiento a Mujeres Rurales. Indicadores para Mujeres y la Igualdad de Género. Recuperado de http://www.economia.gob.mx/files/transparencia/reglas/IMH4IT13.pdf.

SHARMA, M. \& ZELLER, M. (1997): "Repayment performance in group-based credit programs in Bangladesh: an empirical analysis", World Development, 25 (10), 1731-42. Recuperado de: http://www.researchgate.net/publication/5056374_Repayment_Performance_in_GroupBased_Credit_Programs_in_Bangladesh.

SKERTCHLY, R. (2000): Microempresa, financiamiento y desarrollo: el caso de México, $1^{\text {a }}$. ed. México: Universidad Anáhuac del Sur, Grupo Editorial Miguel Ángel Porrúa.

SPENCE, M. (1973): "Job market signaling", Quarterly Journal of Economics, 87, 355-374. Recuperado de: http://www-bcf.usc.edu/ shaddin/cs590fa13/papers/jobmarketsignaling.pdf.

STIGLER, G. (1961): "The economics of information”, Journal of Political Economy, 69 (3), 213-225. Recuperado de: http://home.uchicago.edu/ vlima/courses/econ200/spring01/stigler.pdf.

STIGLITZ, J. (2002): "La Información y el Cambio en el Paradigma de la Ciencia Económica", Revista Asturiana de Economía, 25, 95-164.

STIGLITZ, J. (2007): El Malestar en la Globalización, España: Editorial Taurus.

STIGLITZ, J. (2010): Caída Libre. El libre Mercado y el Hundimiento de la Economía Global, Madrid: Santillana Ediciones Generales, S.L.

STIGLITZ, J. \& WEISS, A. (1981): "Credit Rationing in Markets with Imperfect Information", The American Economic Review, 71 (3), 393-410.

VERA, L., VIVANCOS, F. \& ZAMBRANO, L. (2002): "Un marco Referencial para el Desarrollo de las Microfinanzas en Venezuela", Revista Venezolana de Análisis de Coyuntura, Vol. VIII, No. 2, 233-263.

VICKREY, W. (1961): "Counterspeculation, Auctions and Competitive Sealed Tenders", Journal of Finance, V (16), No. 1, 8-37. Recuperado de: http://www.cs.princeton.edu/courses/archive/spr08/cos444/papers/vickrey61.

YUNUS, M. (1998): Hacia un Mundo sin Pobreza, $1^{a}$. ed. Chile: Editorial Andrés Bello.

ZORRILLA, J. \& RODRÍGUEZ, M. (2010): "El uso de la garantía en los mercados de crédito: una revisión de la literatura empírica", Análisis Económico, 59, vol. XXV. Recuperado de: http://www.analisiseconomico.com.mx/pdf/5906.pdf. 


\section{Anexo 1. Instrumentos}

Tabla 1. Estatus de los Instrumentos

\begin{tabular}{|c|c|c|c|c|c|c|c|c|c|c|c|c|}
\hline \multirow{4}{*}{$\begin{array}{l}\text { SITUACIONES/ } \\
\text { ESTADÍSTICO }\end{array}$} & \multirow{4}{*}{$\begin{array}{l}\text { IDENTIFICACIÓN } \\
\text { INSTITUCIONAL }\end{array}$} & \multicolumn{11}{|c|}{ INSTRUMENTOS } \\
\hline & & \multicolumn{5}{|c|}{ GARANTIA (MONTO) } & \multicolumn{5}{|c|}{ TASA DE INTERÉS (1) } & \multirow{3}{*}{$\begin{array}{l}\text { PRÉSTAMO } \\
\text {-AHORRO (2 }\end{array}$} \\
\hline & & \multirow{2}{*}{ SITUACIONES } & \multirow{2}{*}{ HIPOTECARIA } & \multirow{2}{*}{ PRENDARIA } & \multirow{2}{*}{$\begin{array}{c}\text { AVAL } \\
\text { SOLIDARIO }\end{array}$} & \multirow{2}{*}{ OTROS } & \multirow{2}{*}{ SITUACIONES } & \multirow{2}{*}{ MONTO } & \multirow[b]{2}{*}{ SITUACIONES } & \multicolumn{2}{|l|}{ TIPO } & \\
\hline & & & & & & & & & & FIJA & VARIABLE & \\
\hline Válidos & 192 & 128 & 84 & 56 & 74 & 56 & 128 & & 128 & 81.3 & 18.7 & 67.2 \\
\hline Perdidos & 0 & 64 & & & & & 64 & & 64 & & & \\
\hline Media & & & 148 & 137 & 108 & 83 & & 37,25 & & & & \\
\hline Rango & & 15 & & & & & & 254 & & & & \\
\hline Mínimo & & 1 & & & & & & 10 & & & & \\
\hline Máximo & & 16 & & & & & & 264 & & & & \\
\hline
\end{tabular}

(1) Tasa de interés inicial anual.

(2) Préstamo vinculado al ahorro.

\section{Tabla 2. Garantía}

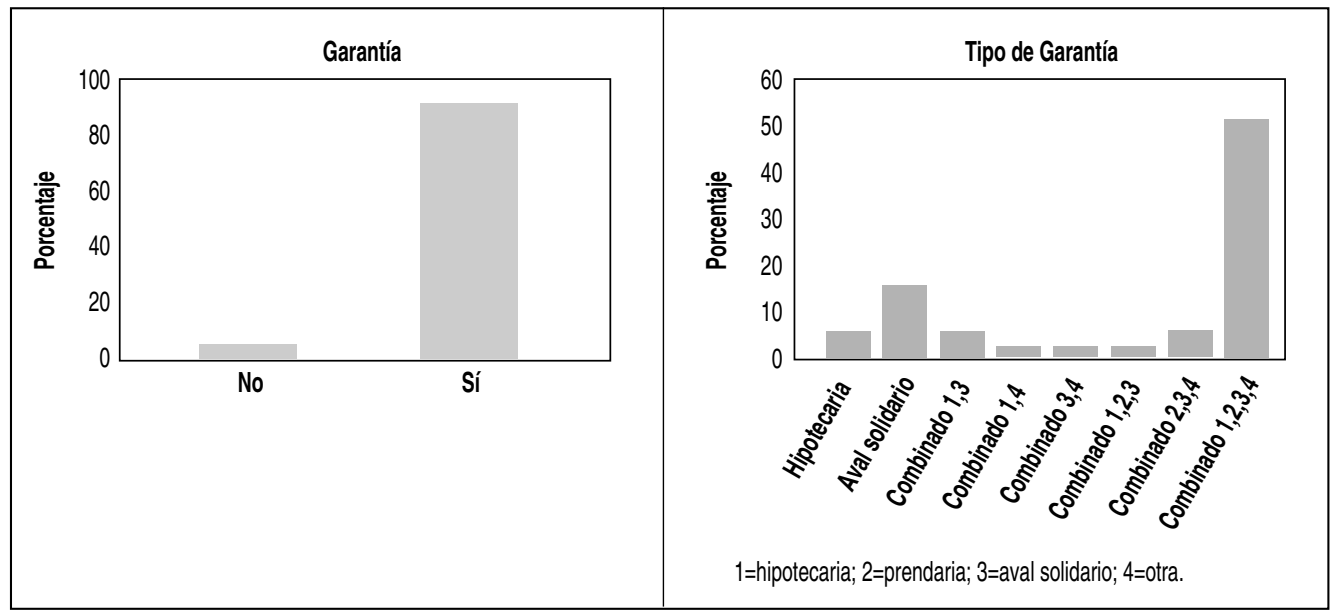

FUENTE: Elaboración propia. 


\section{Tabla 3. Montos de las Tasas de interés y Tasas de Referencia}

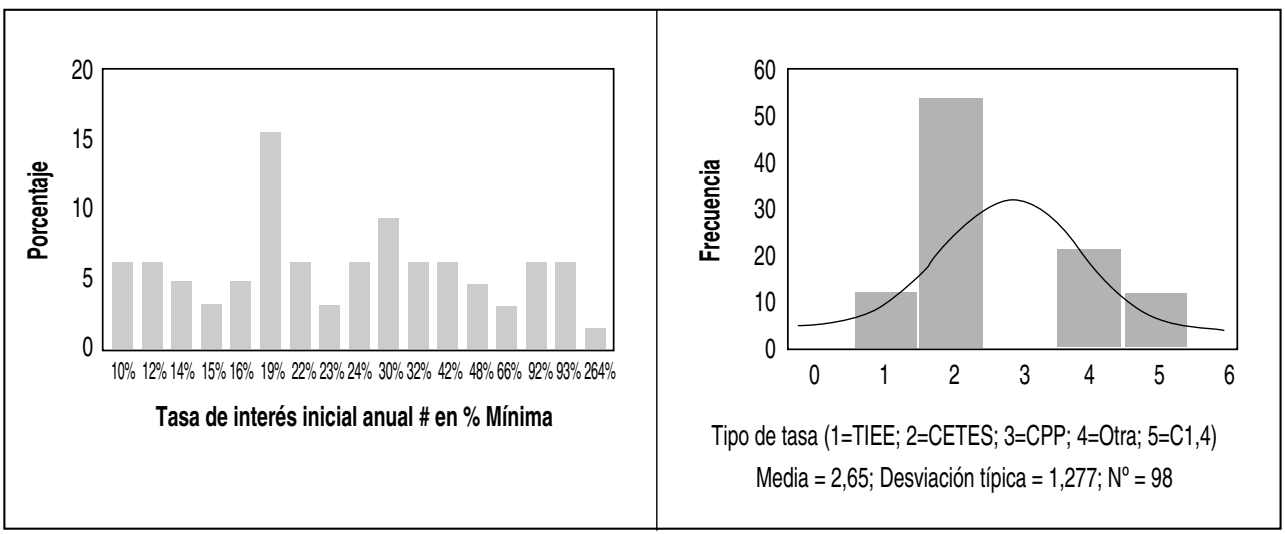

FUENTE: Elaboración propia.

\section{Tabla 4. Tipo de Garantías y Correlación con Tipo de Tasa de Interés}

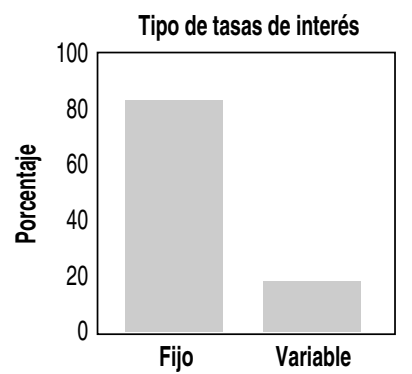

\begin{tabular}{|c|c|c|c|}
\hline \multicolumn{2}{|l|}{ Correlaciones $^{b}$} & $\begin{array}{r}\text { 1=hipotecaria; } \\
\text { 2=prendaria; 3=aval } \\
\text { solidario; 4=otra; } \\
5=\mathrm{C} 1,3 ; 6=\mathrm{C} 1,4 ; \\
7=\mathrm{C} 3,4 ; 8=\mathrm{C} 1,2,3 ; \\
=\mathrm{C} 2,3,4 ; 10=\mathrm{C} 1,2,3,4 .\end{array}$ & $\begin{array}{r}\text { Tipo de } \\
\text { tasa de } \\
\text { interés } \\
\text { 0=Fijo; } \\
\text { 1=Variable }\end{array}$ \\
\hline $\begin{array}{l}\text { 1=hipotecaria; } 2=\text { prendaria; } 3=\text { aval solidario; } \\
\text { 4=otra; } 5=\mathrm{C} 1,3 ; 6=\mathrm{C} 1,4 ; 7=\mathrm{C} 3,4 ; 8=\mathrm{C} 1,2,3 ; \\
\text { 9=C2,3,4;10=C1,2,3,4. }\end{array}$ & $\begin{array}{l}\text { Correlación de Pearson } \\
\text { Sig. (bilateral) } \\
\text { Suma de cuadrados y productos cruzados } \\
\text { Covarianza }\end{array}$ & $\begin{array}{rr} & 1 \\
& 1221.867 \\
10.268\end{array}$ & $\begin{array}{r}-.240^{* *} \\
.008 \\
-36.800 \\
-.309\end{array}$ \\
\hline Tipo de tasa de interés ( $0=F i j 0 ; 1=$ Variable) & $\begin{array}{l}\text { Correlación de Pearson } \\
\text { Sig. (bilateral) } \\
\text { Suma de cuadrados y productos cruzados } \\
\text { Covarianza }\end{array}$ & $\begin{array}{r}-.240^{* *} \\
.008 \\
-36.800 \\
-.309\end{array}$ & $\begin{array}{r}19.200 \\
.161\end{array}$ \\
\hline
\end{tabular}

**La correlación es significativa al nivel 0,01 (bilateral).

b) $\mathrm{N}$ por lista $=120$.

FUENTE: Elaboración propia. 
Tabla 5. El Préstamo vinculado al Ahorro de los prestatarios

\begin{tabular}{|c|c|c|c|c|c|c|c|}
\hline \multicolumn{3}{|c|}{ Estadísticos } & \multicolumn{5}{|c|}{ Préstamo vinculado al ahorro (0/1) } \\
\hline & $\begin{array}{l}\mathrm{N}^{0} \text { identificación } \\
\text { institucional (\#) }\end{array}$ & $\begin{array}{l}\text { Préstamo vinculado } \\
\text { al ahorro (0/1) }\end{array}$ & & Frecuencia & Porcentaje & $\begin{array}{c}\text { Porcentaje } \\
\text { válido }\end{array}$ & $\begin{array}{l}\text { Porcentaje } \\
\text { acumulado }\end{array}$ \\
\hline $\mathrm{N}$ Válidos & 192 & 128 & Válidos & & & & \\
\hline Perdidos & 0 & 64 & No & 42 & 21.9 & 32.8 & 32.8 \\
\hline Media & 8.50 & .67 & sí & 86 & 44.8 & 67.2 & 100.0 \\
\hline Mediana & 8.50 & 1.00 & Total & 128 & 66.7 & 100.0 & \\
\hline Moda & $1^{a}$ & 1 & Perdidos & & & & \\
\hline Desv. tip. & 4.622 & 471 & No sabe & 4 & 2.1 & & \\
\hline Varianza & 21.361 & .222 & No aplicable & 60 & 31.3 & & \\
\hline Rango & 15 & 1 & Total & 64 & 33.3 & & \\
\hline Mínimo & 1 & 0 & Total & 192 & 100.0 & & \\
\hline Máximo & 16 & 1 & & & & & \\
\hline Suma & 1632 & 86 & & & & & \\
\hline Percentiles 25 & 4.25 & .00 & & & & & \\
\hline 50 & 8.50 & 1.00 & & & & & \\
\hline 75 & 12.75 & 1.00 & & & & & \\
\hline
\end{tabular}

FUENTE: Elaboración propia.

\section{Anexo 2. Metodologías}

\section{Tabla 6. Estatus de las Metodologías}

\begin{tabular}{|c|c|c|c|c|c|c|c|c|c|c|c|c|c|}
\hline \multirow{3}{*}{\begin{tabular}{|l} 
SITUACIONES/ \\
ESTADISTICO
\end{tabular}} & \multirow{3}{*}{$\begin{array}{l}\text { IDENTIFICACIONN } \\
\text { INSTITUCIONAL }\end{array}$} & \multicolumn{12}{|c|}{ METODOLOGIA } \\
\hline & & \multicolumn{2}{|c|}{ PRÉSTAMO COLECTIVO } & \multicolumn{2}{|c|}{ BANCA COMUNAL } & \multicolumn{2}{|c|}{ PRÉSTAMO INDIVIDUAL } & \multicolumn{2}{|c|}{ MONITOREO } & \multicolumn{2}{|c|}{ PAGOS FRECUENTES (1) } & \multicolumn{2}{|c|}{ PRESTAMO PROGRESIVO } \\
\hline & & SITUACIONES & $\%$ & SITUACIONES & $\%$ & SITUACIONES & $\%$ & SITUACIONES & $\%$ & SITUACIONES & $\%$ & SITUACIONES & $\%$ \\
\hline \multicolumn{14}{|l|}{ Válidos } \\
\hline Sí & 192 & 20 & 15.6 & 14 & 10.9 & 116 & 90.6 & 112 & 87.5 & 128 & 66.7 & 93.8 & 120 \\
\hline No & 0 & 108 & 84.4 & 114 & 89.1 & 12 & 9.4 & 16 & 12.5 & 64 & 33.3 & 6.3 & 8 \\
\hline \multicolumn{14}{|l|}{ Media } \\
\hline Rango & & 1 & & 1 & & 15 & & 15 & & & & 15 & \\
\hline Mínimo & & 0 & & 0 & & 1 & & 1 & & & & 1 & \\
\hline Máximo & & 1 & & 1 & & 16 & & 16 & & & & 16 & \\
\hline
\end{tabular}

(1) El pago mensual ocupa el $64.8 \%$ de las situaciones estudiadas, mientras que el pago semanal el $10.9 \%$. Además, el $36.7 \%$ de las situaciones equivale a una combinación de pagos mensuales, quincenales y semanales. 